УДК 32.019 .51

\title{
М.В. Кирчанов
}

\section{«КУЛЬТУРА НЕЗНАНИЯ» КАК ФОРМА ИСТОРИЧЕСКОГО ВООБРАЖЕНИЯ И ПОЛИТИЧЕСКОЙ КУЛЬТУРЫ РУССКОГО И БОЛГАРСКОГО НАЦИОНАЛИЗМА}

Автор анализирует образы украинского и македонского языков в политической культуре пользователей Интернета России и Болгарии. Анализируются неакадемические концепции истории и статуса македонского и украинского языков, а также показана зависимость подобных теорий от политической и идеологической конъюнктуры. Предполагается, что анализируемые интерпретации украинского и македонского языков исторически восходят к русскому и болгарскому национализму (последний отрицает существование отдельных македонского и болгарского языков), что автоматически ведет к непризнанию политической легитимности тех стран, где эти языки являются государственными. Автор полагает, что анализируемые уровни политической культуры пользователей интернета, с одной стороны, противоречат основным положениям академической науки. С другой стороны, предполагается, что активность сторонников анализируемых версий истории и современного статуса украинского и македонского языков имеет преимущественно виртуальный характер, способствуя формированию образа врага в политической культуре. Автор полагает, что анализируемые настроения являются чрезвычайно устойчивыми и адаптивными, так как формируют символически значимые измерения русского и болгарского националистического воображения как в продвижении концептов идентичности, так и в формировании образов «Другого».

Ключевые слова: политическая культура, украинский язык, македонский язык, русский национализм, болгарский национализм, «региональная письменная норма болгарского языка», язык, диалект, язык и политика.

DOI: $10.35634 / 2587-9030-2021-5-3-357-366$

\section{Правильная ссылка на статью:}

Кирчанов М.В. «Культура незнания» как форма исторического воображения и политической культуры русского и болгарского национализма // Вестн. Удм. ун-та. Социология. Политология. Международные отношения. 2021. T. 5, вып. 3. С. 357-366. https://doi.org/10.35634/ 2587-9030-2021-5-3-357-366

\section{Формулировка проблемы}

На современном этапе развитие гуманитарных штудий протекает в зависимости от двух формально исключающих друг друга тенденций. С одной стороны, для гуманитарного знания в целом характерны углубляющаяся междисциплинарность и постепенное размывание границ между научными дисциплинами, которые превращаются во фронтиры, содействующие консолидации усилий лингвистов, филологов, историков, специалистов по культуральной истории и культурной антропологии. С другой стороны, несмотря на формальный прогресс гуманитарных наук, количественный рост публикаций, международное сотрудничество в проведении и координации совместных исследований, ряд направлений в современном знании продолжает пребывать в состоянии зависимости от идеологической конъюнктуры и политических предпочтений правящих элит.

В этой ситуации научное знание не только сталкивается с давлением со стороны государства как основного спонсора науки, но и оказываются в состоянии конкуренции с новыми противниками, которые появились на волне общей виртуализации современного общества в начале 21 века. С такими политическими вызовами сталкиваются не только исследователи, которые занимаются изучением проблем, представляющих непосредственный интерес для элит, но и те интеллектуалы, которые вовлечены в штудии славянской филологии, в частности в изучение македонского и украинского языков. Македонский и украинский языки, являющиеся славянскими, принадлежащие к различным подгруппам, имеют статус государственных соответственно на территории Северной Македонии и Украины, отношения которых с их соседями - Болгарией и Российской Федерацией - на современном этапе отягощены комплексом различных исторических и политических взаимных претензий и противоречий.

Общий политический фон идеологизации изучения украинского и македонского языков в достаточной степени описан в академической историографии. Поэтому ограничимся только кратким перечислением внешних факторов, которые существенно влияют на идеологизацию формально академических исследований: Болгария официально не признает существование македонского языка, оп- 
ределяя его в качестве региональной нормы болгарского; в 2014 г. Крым вошел в состав Российской Федерации, а на территории Луганской и Донецкой областей Украины начался военный конфликт, что существенно обострило украино-российские отношения; и Северная Македония, и Украина в рамках своего национального права приняли законы, регулирующие использование языков, придав государственный статус соответственно македонскому и украинскому", что вызвало недовольство со стороны Софии и Москвы.

\section{Цель и задачи статьи, источниковый корпус}

В центре авторского внимания в данной статье - формирование образов Другого в интернетсегментах болгарской и российской политических культур, проявляющееся в неакадемических подходах в современной украинистике и македонистике, основанных на отрицании существования украинского и македонского языков. Между отрицанием украинской и македонской идентичности в русском и болгарском националистическом воображении просматриваются параллели, а именно: украинская идентичность и македонская идентичность воспринимаются как неправильные и незавершенные версии соответственно русской и болгарской, их появление связывается с негативным и сознательным влиянием и воздействием внешних факторов, украинский и македонский языки воспринимаются как диалекты русского и болгарского. Поэтому целью статьи является сравнительный анализ политически и идеологически мотивированных интерпретаций, связанных с продвижением нарративов несуществования украинского и македонского языков, что составляет часть политической культуры России и Болгарии на уровне формирования концептов самости и инаковости.

Несмотря на то что «в среде профессиональных филологов возникает когнитивный конфликт» [1], когда они вынуждены читать неакадемические тексты по украинистике и македонистике, фольклингвистические интерпретации украинского и македонского языков нуждаются в изучении. Поэтому задачами статьи следует признать компаративный анализ аргументации сторонников анализируемых концепций; изучение особенностей изучаемого дискурса политической культуры в его зависимости от националистической идеологии; анализ восприятия рассматриваемых уровней политической культуры современными интернет-пользователями, так как большинство авторов изучаемых текстов ориентированы на отзывы своих виртуальных читателей и, реагируя на них, совместными усилиями формируют «язык вражды», который в ряде сегментов российского и болгарского интернета определяет отношение не только к украинскому и македонскому языкам, но и к самим украинцам и македонцам, статус которых как наций оспаривается, а македонскому и украинскому государствам приписываются атрибуты и характеристики классических Других, включая неполноценность, ущербность и нелегитимность, что фактически ведет к формированию и продвижению образов врага.

Исходя из подобных задач и цели, источниковый корпус представлен интернет-публикациями на сайтах неакадемической, но политической и популярной направленности, которые не только позволяют пользователям оставлять свои комментарии, но и при условии регистрации дают им возможность самостоятельной публикации текстов.

\section{Политизация науки и неакадемические формы «знания»}

В этой ситуации македонский и украинский языки в Болгарии и России стали частью местной информационной повестки дня, что вдохновило волну неакадемических публикаций, авторы которых не только отрицают существование этих языков, но и не признают ни македонцев, ни украинцев в качестве самостоятельных наций и, как следствие, высказывают сомнения в легитимности Украины и Македонии как государств. Подобные публикации в целом актуализируют как минимум две тесно связанные между собой проблемы российского и болгарского общества.

С одной стороны, активные дебаты в виртуальных средах относительно украинского и македонского языков свидетельствуют о растущей политизации и идеологизации славянской филологии,

\footnotetext{
* В Северной Македонии государственным также является и албанский, что для Софии второстенно, так как согласно официальной точке зрения Болгарии македонского языка не существует и в его отношении используется термин «региональная письменная норма болгарского языка». Несмотря на то что академическое славяноведение в России не отрицает самостоятельный статус украинского языка, в российском виртуальном и информационном пространстве свободно доступны тексты, авторы которых воспринимают украинский язык не как самостоятельный, но как диалект русского.
} 
хотя академическая славистика предпочитает эти тенденции игнорировать. С другой стороны, политизация изучения этих языков фактически на национальном уровне санкционировала отказ от академической монополии в их изучении, породив и вдохновив массу неакадемических и откровенно лженаучных публикаций, авторы которых, апеллируя к политическим и идеологическими ценностям, не только претендуют на выражение собственной точки зрения, но и стремятся к делигитимации в обществе академической науки как чрезвычайно строгой и академической, игнорирующей политический заказ.

В результате виртуальные пространства российского и болгарского интернета становятся теми сферами, где разворачиваются так называемые холивары - неакадемические дискуссии, участники которых, не принимая во внимание мнение оппонентов, втянуты в продвижение тех или иных политических идеологий, что фактически ведет в дискредитации академической науки и падению ее авторитета в обществе, так как сами академические исследователи предпочитают в таких ситуациях занимать позицию подчеркнутого нейтралитета, отстраняясь от дилетантов и непрофессионалов, которые предлагают своим читателям неакадемические, но популярно написанные тексты, противоречащие, как правило, современной науке. Как следствие, определенные сегменты российского и болгарского общества склонны воспринимать неакадемическую точку зрения, синтезированную с положениями соответствующего политического мифа, связанного с русским или болгарским национализмом. Формально пострадавшей стороной в этой ситуации оказывается академическая наука, в той или иной мере зависящая от политической ситуации и не противостоящая с достаточной эффективностью неакадемическим построениям непрофессионалов, которые более видимы и заметны в современных медийных пространствах общества потребления.

\section{«Культура незнания» как элемент политической культуры национализма}

Уместно констатировать появление в рамках современных политических культур России и Болгарии так называемой «культур незнания», которые самым тесным образом оказались связаны с традициями соответственно русского и болгарского этнического национализма. «Культуры незнания» основаны на воспроизводстве унаследованных от предыдущих поколений интеллектуалов созданных и предложенных ими политических мифов и стереотипов, используемых как для актуализации концептов самости, так и продвижения образов Другости и Инаковости. Анализируемые версии «культуры незнания» склонны оперировать преимущественно примордиальными категориями, что ведет к восприятию Других в рамках националистического воображения как неправильных образов Себя. В этом контексте «культура незнания» как сегмент политической культуры того или иного этнического национализма последовательно отрицает достижения модернистского поворота, воспринимая категории «нация» и «язык» как внеисторические. В рамках политизированных версий «культуры незнания» объективные исторические перемены в статусе групп и их идиомов игнорируются, а на анализируемые явления носителями «культуры незнания» сознательно или несознательно проецируются современные политические стеретипы. Кроме этого, основные положения «культуры незнания» резко контрастируют с современными достижениями гуманитарных наук в целом. В анализируемом в данной статье случае речь идет о славянской филологии, так как консенсусное признание большинством представителей академического сообщества существования македонского и украинского языков отрицается авторами, чьи тексты использованы в качестве источников в данной статье.

\section{Этнический национализм большинства и «культуры незнания» в России и Болгарии}

Фольк-лингвистические интерпретации украинского и македонского языков на Украине и в Болгарии самым тесным образом связаны с политическими внешними стимулами, будучи фактически ответом общества на националистические запросы элит. Неакадемическое восприятие украинского и македонского языков в российском и болгарском случаях развиваются в значительной степени очень сходно, демонстрируя общие механизмы как формирования, так и продвижения фольклингвистических нарративов.

Фольк-лингвистические объяснения украинского и македонского языка основаны на консенсусе их сторонников в том, что таких языков не существует. Поэтому и российские, и болгарские авторы фольк-лингвистических текстов часто используют термины «недоязык» [21] и «псевдоязык» [8], которые в языкознании не употребляются. Если российские авторы, идеи которых могут быть в отношении 
украинского языка определены как ненаучные и фольк-лингвистические, определяют его как диалект русского, то болгарские интеллектуалы, отрицающие самостоятельный статус македонского, склонны писать о нем как о «форме болгарского языка» [18], «болгарском диалекте», «северомакедонском болгарском диалекте» [5] или «региональной письменной норме болгарского языка» [2], что фактически равнозначно восприятию македонского как диалекта с ограниченными социальными функциями.

Общим местом в неакадемических попытках «изучения» украинского языка, например, является утверждение, что язык создан искусственно, а основной лексический фонд основан по принципу сознательного искажения лексики русского языка [6]. Аналогичные мнения заметны и в болгарском общественном мнении в отношении македонского языка, например, версия, что «“македонский язык” является вторичной нормой литературного болгарского языка и всегда был неотъемлемой и неотделимой частью нашего родного духовного наследия» [30] или «юго-западной письменной региональной нормой болгарского языка» [20]. Поэтому «провести четкие границы между фольк-лингвистикой и научной лингвистикой не всегда возможно; некоторые теоретические построения лингвистов-специалистов мало чем отличаются от самых наукообразных теорий фольк-лингвистических авторов» [23], о чем, например, свидетельствует опыт развития академического языкознания в Болгарии, где на официальном уровне не признается существование ни македонского языка, отличного от болгарского, ни македонской нации, воспринимаемой в качестве этнографической группы болгар. В этом контексте и украинский, и македонский языки и, как результат, украинцы и македонцы могут восприниматься некоторыми авторами как часть болгарской или русской идентичности, как ее региональные версии со значительными локальными особенностями. В отношении украинского языка сторонники фольк-лингвистики настаивают, что «украинский язык является одним из многочисленных диалектов русского языка, который был просто изнасилован польскими заимствованиями и грамматикой» [29].

Если российские сторонники фольк-лингвистики одиноки в своем отрицании существования украинского языка, то многие интеллектуалы и политики в Болгарии солидарны в своей вере в то, что македонский язык является только одним из диалектов болгарского, что, правда, дает результаты, отличные от тех, на которые рассчитывают те, кто думает подобным образом. Такая позиция как политических элит, так и интеллектуальных сообществ в современной Болгарии стимулирует рост македонского национализма в Северной Македонии [35]. Несмотря на то что отрицание украинского языка со стороны русских националистов приводит к аналогичным последствиям на Украине, они тем не менее последовательны в продвижении именно такого нарратива. Например, один из анонимных пользователей российского сервиса «Яндекс дзен» склонен определять украинский язык следующим образом: «малорусское наречие - древнерусский язык средневековой Руси, обильно разбавленный польскими заимствованиями. Обиходное наречие села» [36].

Некоторые болгарские и российские авторы готовы признать существование украинского и македонского языков, но исключительно на уровне диалекта. В частности, болгарский филолог Анна Кочева подчеркивает, что, «когда мы говорим, что существует македонский болгарский язык, мы имеем в виду родовое понятие болгарского языка и разновидность македонского языка» [14], что предусматривает редукцию македонского до региональной версии болгарского. Кроме этого, в отношении украинского языка большинство авторов фольк-лингвистических текстов солидарны в том, что украинский - это «испорченный диалект русского, придумка недалеких националистов, разработка австрийского Генштаба и свидомых националистов революции 1917 года, эксперименты советских лингвистов» [33].

В аналогичной стилистике пишут и некоторые болгарские авторы, которые настаивают на том, что среди славянских языков македонского не существует [20], так как он представляет собой конструкт, намеренно созданный политиками [15]. Другие и вовсе утверждают, что украинский язык возник в результате «демонической» национальной политики советской власти [12], в то время как болгарские интеллектуалы более осторожно указывают на то, что болгарский язык является плюроцентричным, что позволяет им интерпретировать македонский как один из болгарских диалектов [10].

\section{Политическая культура и культура «незнания»}

Сторонники фолк-лингвистического подхода разделяют основные положения «теории заговора», распространяя их на украинский и македонский языки, воспринимая последние как следствие антироссийской или антиболгарской политики внешних враждебных сил. Анонимный пользователь канала «История России» российского сервиса «Яндекс дзен» полагает, что «украинский язык был придуман в 
австрийском Генштабе» [31]. Болгарские авторы, в свою очередь, в отношении македонского языка настаивают, что он был искусственно создан сербскими коммунистами при участии Москвы [24].

Поэтому ряд активных авторов современной российской фольк-лингвистики утверждает, что украинский язык представляет собой «корявый новоиспеченный польско-галицкий жаргон» [36], а среди болгарских интеллектуалов относительно македонского языка распространено мнение, что он является сознательно испорченным болгарским, в который внедрили французские и латинские заимствования [24]. Относительно украинского языка большинство его фольк-лингвистических концепций сводится к тому, что он был намеренно создан внешними врагами России. В зависимости от политических и идеологических предпочтений авторов неакадемических лингвистических теорий на статус таких врагов могут претендовать поляки или австрийцы. Пользователь российского сервиса «Яндекс дзен» под именем «Олег Варягов», например, категорически утверждает, что «поляки родили "Украину”, “украинцев”», что, по его мнению, вписывалось в «логику фальсификации и обмана». Тот же «Олег Варягов» указывает и на якобы особую роль евреев в появлении украинского языка, настаивая, что «созданию Украины и насаждению украинского языка современная Украина обязана не украинским националистам и не Степану Бандере, а партии большевиков и руководителю КП(б)У - еврею Лазарю Моисеевичу Кагановичу. Аминь» [6].

Другие сторонники фольк-лингвистического подхода подчеркивают, что украинский язык был придуман Веной как «политическое орудие для отторжения Украины от России» [31]. Аналогичная риторика доминирует и в болгарских публикациях о македонском языке, в которых его кодификатор Блаже Конески воспринимается как фальсификатор и «ревностный сторонник сербизации» болгар Македонии [19]. Если для российских авторов, которые фактически воспроизводят неакадемический фольк-лингвистический дискурс, украинский язык - не более чем польская или австрийская попытка отторгнуть украинцев от России, то в рамках болгарского националистического дискурса македонский язык только шаг на пути к сербизации.

\section{Формирование образов Другого: политические функции «культуры незнания»}

Практически все фольк-лингвистические интерпретации украинского и македонского языков в большей или меньшей степени актуализируют язык вражды, что ведет к формированию негативного образа македонцев / Македонии и украинцев / Украины как универсальных Других или неправильных Своих. Если авторы фольк-лингвистических публикаций стремятся избегать открыто формировать и продвигать образы Других, предпочитая проецировать на украинский язык внутрироссийскую политическую повестку дня [34], то анонимные интернет-пользователи, которые пишут комментарии к их постам, более радикальны, настаивая, например, на том, что «этот язык только с перепою мог появиться... собаки понятней лают» [31] или «украинская мова это испогненый (так в источнике. - M.K.) русский язык» [31] или «“украинский язык” - это не более чем местечковое наречие Русского языка... на основе безграмотного говора сельского населения и “псевдоязык” состоящий из заимствований и исковеркованного (так в источнике. - M.K.), безграмотного русского языка» [31].

В свою очередь, в болгарских СМИ доминирует мнение относительно македонского языка как «другого названия болгарского языка», что позволяет некоторым авторам воспринимать македонский язык как диалект болгарского [7]. Некоторыми авторами фольк-лингвистических текстов утверждается, что «нынешняя укромова выглядит недалёкой детской игрой в слова, где дотошно выпилены или исковерканы русские корни» [8], хотя в других своих текстах они более радикальны, утверждая, что «тарабарский польско-русинский “суржик»” изобрели в Галиции на деньги австрийского Генштаба... Его вообще по эстетическим причинам в геену (так в источнике. - M.К.) лингвистическую следовало отправить, до скончания мира» [27]. Поэтому для российских и болгарских авторов, склонных отрицать существование украинского и македонского языков, характерно собственное позиционирование как подлинных ученых, в то время как их оппоненты обвиняются ими в политизации и идеологизации науки [2]. В этом контексте очень показателен общий низкий уровень культуры цитирования в подобных текстах, где ссылки на работы, принадлежащие к академической науке, как правило, отсутствуют.

Вместо цитирования сторонники фольк-лингвистики «либо просто упомянут, либо заклеймят какой-нибудь хлесткой эмоционально окрашенной фразой» [4] те концепции, которые в их точку зрения не вписываются. Некоторые сторонники фольк-лингвистического подхода к македонскому и украинскому языкам придерживаются радикальных позиций и вовсе настаивают, что государства, 
где эти языки имеют официальный статус, должны быть ликвидированы, а местное население соответственно русифицировано и болгаризировано. В частности, болгарский филолог Е. Сачев настаивает на том, что «сегодняшние власти Македонии вместо того, чтобы исправлять ошибки своего политического прошлого; вместо того, чтобы очистить себя и своих граждан от пагубных заблуждений и культурного геноцида югославского сербизма, советского интернационализма и сербомакедонизма, они продолжают отравлять умы своего молодого поколения неправдой и абсурдом относительно своего этнического, исторического и культурного происхождения. Путь, выбранный нынешними македонскими властями, ведет не к Европейскому союзу, а к самоуничтожению» [25].

Среди комментариев пользователей доминируют негативные высказывания, которые нередко сводятся к утверждениям, что «украинство - искусственно созданное евреями - глобалистами (так в источнике. - M.К.) течение по смене мышления, сознания» [3], а «украинский язык это местичковый (так в источнике. - M.K.) диалект русского, а все остальное это бред... дело в том что те области где говорят на малороссийском диалекте по долгу находились в подчинении поляков, литвы, турок... так сложился этот говор, который затем искусственно ушлые националисты превратили в мову» [11]. Комментаторы, которые формируют негативный образ украинского языка, также склонны продвигать фольк-лингвистический дискурс, утверждая, что «украинский язык не является самостоятельным, состоит из $70 \%$ русских слов, $15 \%$ польских, $10 \%$ румынских, остальные из языков соседних государств» [11], правда, избегая при этом ссылок на источник, что в целом отражает основные закономерности функционирования политической культуры национализма, основанной на авторитете мифа, нежели на обращении к результатам, получаемым в результате академических исследований.

\section{Политически мотивированная фальсификация данных как особенность политической «куль- туры незнания»}

Сторонники фольк-лингвистических интерпретаций украинского и македонского языков склонны к фальсификации данных, приводя, например, в качестве иллюстраций своей точки зрения несуществующие слова, утверждая, что таковые являются украинскими. Истоки таких фальсификаций различны, но, как полагал А. Зализняк, их генезис может быть связан с невидимостью академической лингвистики в современном обществе в силу того, что «такого рода любительские построения полностью игнорируют достижения научного языкознания. Поскольку, увы, эти достижения научного языкознания крайне мало известны» [9]. Например, пользователь сервиса «Яндекс дзен» под именем «Олег Варягов» утверждает, что рус. «табурет» в украинском языке соответствует «підсральник», а «коробке передач» - «скринька перепихунців» [6], игнорируя тот факт, что такие лексемы в современном литературном украинском языке отсутствуют.

Такие «интерпретации» практически полностью основаны на игнорировании академической науки, так как «настоящий лингвист, объясняя происхождение некоторого слова, предлагая для некоторого слова гипотетическую этимологию, то есть происхождение из некоторой другой формы, которая отличается, скажем, в трёх точках от нынешнего слова, обязан представить объяснение для каждой из этих трёх точек, для каждой из них должен показать, почему она должна была измениться ровно так, как мы сейчас видим, а не как-нибудь произвольно. Ничего подобного, конечно, в любительских построениях не бывает, там решительно всё что угодно может заменяться на всё что угодно по воле сочинителя» [9]. Именно такие тенденции заметны и в рамках болгарского восприятия македонского языка, определяемого как «коминтерновская креатура, созданная по указу и партийному заказу» [17], «плод политической инженерии» [13] и сознательного «сочинительства» после Второй мировой войны [16].

Поэтому значительная часть болгарских авторов не только воспринимает его историю как историю одного из диалектов болгарского, но и настаивает, что на протяжении этой истории внешние силы сознательно и намеренно стремились «превратить болгарский диалект в литературный язык» [22]. Другим проявлением неакадемического характера фольк-лингвистических интерпретаций украинского языка являются утверждения о том, что украинский - это русский язык с применением «исковерканных польских, немецких, чешских слов» [36]. Аналогичный подход характерен и для болгарских авторов, которые склонны утверждать, что македонский язык является диалектом болгарского, намеренно отдаленным и отделенным элитами от болгарской основы путем «создания на основе болгарской лексики некой новой лексики, которая отличалась бы от болгарской» [28]. Вероятно, наиболее ярким примером фальсификации является утверждение канала «Международная жизнь» на 
«Яндекс дзен», автор которого утверждает, что «украинский язык следует рассматривать как диалект русского языка, и это известно любому непредубеждённому филологу» [32], игнорируя тем самым академически признанные типологии славянских языков.

Отрицание существования украинского и македонского языков в русском и болгарском националистическом воображении стало общим местом. Болгарские авторы, например, последовательно интегрируют македонские нарративы в контексты именно болгарской исторической памяти, отрицая само существование македонской идентичности и настаивая на том, что «национальная самобытность и культурное единство болгарского населения в болгарском регионе с историко-географическим названием "Македония", а также тот факт, что это население является неотьемлемой частью остального болгарского народа, подчеркиваются в ряде исследований, написанных авторами с бесспорным болгарским сознанием периода Возрождения, многие активисты которого происходили из Македонии» [26], что фактически интегрирует македонскую историю в болгарские контексты, редуцируя ее до уровня региональной формы болгарского исторического процесса.

\section{Выводы}

Подводя итоги статьи, во внимание следует принимать ряд факторов, которые определяют основные векторы и траектории развития и функционирования фактический фольк-лингвистического и неакадемического дискурса в современных российских и болгарских интернет-пространствах в тех случаях, когда в центре псевдонаучных текстов оказываются проблемы украинской и македонской филологии, а сами тексты становятся элементами политической культуры, точнее соответствующих субкультур русского и болгарского национализма.

Во-первых, современные неакадемические интерпретации македонского и украинского языков, основанные на их неприятии и отрицании, неоригинальны, будучи вторичными и упрощенными попытками популяризации и адаптации для потребностей политически мотивированных сегментов общества потребления идей болгарского и русского национализма. Поэтому большинство идей и положений проанализированных выше интернет-публикаций раннее было озвучено в текстах, формирующих корпус классических источников идеологии русского и болгарского национализма, а именно тех его идеологов, которые «специализировались» на критике соответственно «украинства» и «македонизма».

Во-вторых, фольк-лингвистическое отрицание македонского и украинского языков основаны на игнорировании достижений академической македонистики и украинистики в частности, а также истории и языкознания в целом. В этой ситуации общий уровень анализируемых выше публикаций является крайне низким, так как их авторы не имеют ни исторического, ни филологического образования и поэтому не обладают компетенциями, необходимыми для академического анализа ни украинского, ни македонского языков, хотя таковые цели они себе в принципе не ставят, будучи сфокусированными на последовательном воспроизводстве отдельных положений русского или болгарского националистического мифа, так как воспринимают последние в качестве универсальных инструментов для интерпретации, точнее для отрицания как украинских, так и македонских особенностей и явлений лексики и грамматики. В этом случае, правда, следует признать и то, что авторы большинства анализируемых выше текстов не утруждают себя серьёзными исследованиями в сфере украинской и македонской филологии, полагая, что любительской интерпретации и связанной с ней политически мотивированной и идеологически вдохновленной аргументации более чем достаточно.

B-третьих, неакадемические и фольк-лингвистические концепции украинского и македонского языков являются составными элементами как украинофобии, так и македонофобии, будучи составными элементами как соответствующих националистических дискурсов, в том числе основанных и на формировании и продвижении «языка вражды». Появление анализируемых выше текстов, по мнению автора, ситуативно и непосредственно зависит от политической конъюнктуры, будучи реакцией на периодически имеющие место кризисы соответственно в болгаро-македонских и российскоукраинских отношениях.

B-четвертых, широкое распространение проанализированных выше фольк-лингвистических подходов не только стало следствием растущей виртуализации современного общества, но было простимулировано также кризисом академического знания, разрывом и разрушением коммуникационных каналов между наукой и обществом, в результате чего место, ранее занимаемое научно-популярной продукцией, в том числе и по языкознанию, оказалось занято разного рода дилетантами, активно создающими псевдонаучные тексты, в том числе в сфере македонской и украинской филологии. Поэтому в 
современной фольк-лингвистике сложились течения, основанные на (вос)производстве неакадемических и лженаучных интерпретаций политического характера, отрицающих существование украинского и македонского как самостоятельных славянских языков. Такие идеи следует анализировать в рамках более широкого дискурса русского и болгарского националистического воображения, где отрицание украинской и македонской идентичности стало составным элементом как непризнания существования соответствующих наций и идентичностей, так и делигитимации самой современной государственности Украины и Северной Македонии.

Таким образов, фольк-лингвистические «штудии» вторичны не только по своему содержанию в силу его неоригинальности и воспроизводства адаптированного и упрощенного более раннего болгарского или русского национализма, но и в силу того, что такие ненаучные и неакадемические лингвистические теории интегрированы в более широкие контексты современного националистического воображения, редуцированного в условиях как виртуализации, так и развития общества потребления до феномена интернет-«холиваров», развивающихся параллельно с академической наукой, будучи основанными на ее отрицании и стабильно расширяя корпус источников последней, обеспечивая историков национализма и специалистов по политической лингвистике новыми текстами, актуализирующими различные формы как националистического воображения, так и его смыкания и пересечения с неакадемическими фольк-лингвистическими интерпретациями.

В целом анализируемые настроения в политических культурах России и Болгарии в отношении македонской и украинской идентичности, с одной стороны, виртуальны, а с другой - принадлежат к так называемой культуре незнания, основанной на авторитете воспроизводимых националистических мифов, а также на континуитете в развитии образов и концептов «инаковости» как ошибочной и неправильной «Самости», что характерно для политической культуры как русского, так и болгарского национализма.

\section{СПИСОК ЛИТЕРАТУРЫ}

1. Базылев В.Н. Политика и лингвистика: «великий и могучий...» // Политическая лингвистика. Екатеринбург: Издательство Уральского университета, 2009. Вып. 3(29). С. 9-39.

2. Билярски Ц. С аргументите на науката българските езиковеди разгромиха скопските фалшификатори през 1978 г. URL: http://www.sitebulgarizaedno.com/index.php?option=com_content\&view=article\&id=592:--------1978-\&catid=29:2010-04-24-09-14-13\&Itemid=61 (дата обращения: $10.0 \overline{6} .2021$ )

3. Булгаков и украинский язык // Забытые истории. 2019. 30 октября. URL: https://zen.yandex.ru/media/ sergeytsvetkov.livejournal.com/bulgakov-i-ukrainskii-iazyk-5db868b90a451800ac97c903 (дата обращения: 10.06.2021).

4. Бурлак С. Лженаука о языке: дифференциальный диагноз // Троицкий вариант. 2013. №13 (132). 2 июля. URL: https://trv-science.ru/2013/07/lzhenauka-o-yazyke-differencialnyjj-diagnoz/ (дата обращения: 10.06.2021).

5. В Северна Македония говорят на български диалект. В ново научно издание се предлага да се въведе понятието «северномакедонски български език» // Площад Славейков. 2020. Май 8. URL: https://www.ploshtadslaveikov.com/ban-v-severna-makedoniya-govoryat-na-balgarski-dialekt/ (дата обращения: 10.06.2021).

6. Варягов О. Кто, когда и зачем придумал украинский язык. URL: https://zen.yandex.ru/media/olegvaragov/ktokogda-i-zachem-pridumal-ukrainskii-iazyk-60b31687f8cd844b4ec6cb12 (дата обращения: 10.06.2021).

7. Велев Г. Исторически извори доказват, че т.нар. македонски е другото име на българския език. Откъс от «История на българите от Македония» // Животът днес. 2020. Декември 5. URL: http://www.jivotatdnes.bg/ nachalo/news/balgarshtina/istoricheski-izvori-dokazvat-che-tnar-makedonski-e-drugoto-ime-na-balgarskiya-ezik (дата обращения: 10.06.2021).

8. Государственный язык ненависти: каково жить умному украинцу? // Исторические наперстки. 2021. 18 апреля. URL: https://zen.yandex.ru/media/id/5ef8896c0d13dd78e21972de/gosudarstvennyi-iazyk-nenavisti-kakovojit-umnomu-ukraincu-607bfd11 eac7203d7589fсa0 (дата обращения: 10.06.2021).

9. Зализняк А. О ложной лингвистике и квазиистории // Скепсис. 2015. 14 марта. URL: https://scepsis.net/ library/id_3643.html (дата обращения: 10.06.2021).

10. Златанов И. Откога има български език? Македонският език ли е или диалект. Кога българите започват да се самоопределят като българи и откога има български език // Вести. 2020. Декември 8. URL: https://www.vesti.bg/ bulgaria/otkoga-ima-bylgarski-ezik-makedonskiiat-ezik-li-e-ili-dialekt-6118627 (дата обращения: 10.06.2021)

11. Как появился украинский язык и при чём тут санскрит? // Грамотно! 2018. 23 ноября. URL: https://zen.yandex.ru/media/gramotno/kak-poiavilsia-ukrainskii-iazyk-i-pri-chem-tut-sanskrit-5bf626285184cc00a9 90329d (дата обращения: 10.06.2021). 
12. Корни и тайны украинского и русского языков? Аналитика (почти) без политики // Исторические наперстки. 2021. 11 мая. URL: https://zen.yandex.ru/media/id/5ef8896c0d13dd78e21972de/korni-i-tainy-ukrainskogo-irusskogo-iazykov-analitika-pochti-bez-politiki-609a87d6d0fd62728bb7c3ec (дата обращения: 10.06.2021).

13. Кочева А. Историята на т.нар. македонски книжовен език е българска // Глас Пресс. 2020. Май 27. URL: https://glaspress.rs/доц-ана-кочева-историята-на-т-нар-маке/ (дата обращения: 10.06.2021)

14. Кочева А. Постои ли «македонски јазик?» // Консерваторъ. 2019. Декември 18. URL: https://conservative.bg/ ima-li-makedonski-ezik/ (дата обращения: 10.06.2021)

15. Кочева А. Проблемът с т. нар. «македонски език» си е на Скопие // БHР Хоризонт. 2020. Ноември 11. URL: https://bnr.bg/horizont/post/101374830/doc-anna-kocheva-problemite-s-tnar-makedonski-ezik-sa-si-na-skopie (дата обращения: 10.06.2021)

16. Кочева А. Що е то «македонски език» и може ли да бъде официално признат в EC // Dir.bg. 2018. Декември 12. URL: https://dnes.dir.bg/obshtestvo/shto-e-to-makedonski-ezik-i-mozhe-li-da-bade-ofitsialno-priznat-v-es (дата обращения: 10.06.2021)

17. Македонският език е български диалект // Frognews. 2007. Февруари 22. URL: https://frognews.bg/politika/makedonskiiat-ezik-balgarski-dialekt-2017-05-17.html (дата обращения: 10.06.2021)

18. «Македонският» е форма на българския език. Става дума за националната ни идентичност и за националния ни суверенитет и сигурност днес // Дума. 2019. Декември 18. URL: https://duma.bg/ban-makedonskiyat-eforma-na-balgarskiya-ezik-n205603 (дата обращения: 10.06.2021)

19. Марковска Ф. Блаже Конески - фалшификатор и създател на македонската азбука и език // Македония. 1998. Бр. 12. Март 25. URL: http://promacedonia.com/v_mak/1998/mak_ezik.html (дата обращения: 10.06.2021)

20. Мичева В. Македонски език има, но е с български произход // Трета възраст. Национален назависим седмичник. 2020. Юни 30. URL: https://www.tretavazrast.com/articles/доц-ваня-мичева-македонски-език-има,-ное-с-български-произход (дата обращения: 10.06.2021)

21. Недоязык и недоводка // Спорт, спирт, книжки. 2021. 5 мая. URL: https://zen.yandex.ru/media/ $\mathrm{id} / 5 \mathrm{ea} 4025 \mathrm{a} 77 \mathrm{~d} 8 \mathrm{ae} 2565819938$ /nedoiazyk-i-nedovodka-609258fade56f009bcf9c77e (дата обращения: 10.06.2021)

22. «Подмененият език»: Преврьщането на един български диалект в книжовен език // Plovdiv24.bg. 2021. Януари 11. URL: https://www.plovdiv24.bg/novini/Bylgaria/Podmeneniyat-ezik-Prevrushtaneto-na-edin-bulgarskidialekt-v-knizhoven-ezik-1038559 (дата обращения: 10.06.2021)

23. Полиниченко Д.Ю. Фольк-лингвистика как объект научного изучения // Обыденное метаязыковое сознание: онтологические и гносеологические аспекты. Кемерово - Барнаул: Издательство Алтайского университета, 2009. Вып. 1. С. $67-87$.

24. Попвасилева Б. Още за «македонския» език и за «македонския» народ // Македония. 1998. Бр. 12. Март 25. URL: http://promacedonia.com/v_mak/1998/mak_ezik.html (дата обращения: 10.06.2021).

25. Сачев Е. Ето как е създаден «македонският език»: проф. Евгений Сачев за Фалшификацията с /т.нар./ «македонски език» // Брод за България. 2021. Януари 29. URL: https://www.brodbg.com/news-4-1007-Eto_ kak_e_sazdaden_makedonskiyat_ezik.html (дата обращения: 10.06.2021).

26. Сачев Е. Македонизмът е културен тероризъм. България трябва да не прави никакъв компромис със своята история, култура и език // Брод за България. 2021. Януари 19. URL: https://www.brodbg.com/news-3-1004Makedonizmat_e_kulturen_terorizam.html (дата обращения: 10.06.2021).

27. Свидомые мифы: как москали «украинскую мову» запрещали-запрещали... // Исторические наперстки. 2021. 17 мая. URL: https://zen.yandex.ru/media/id/5ef8896c0d13dd78e21972de/svidomye-mify-kak-moskaliukrainskuiu-movu-zaprescalizaprescali-60a2722864e0436175af8873 (дата обращения: 10.06.2021).

28. Стоилов А. Македонски език? Езиковият спор: время за сьтрудничество или время за инат // Инфомрежа. 2020. Февруари 14. URL: http://infomreja.bg/makedonski-ezik-ezikoviqt-spor---vreme-za-sytrudnichestvo-ilivreme-za-inat-chast-1-74050.html?reg=2 (дата обращения: 10.06.2021).

29. Существует ли украинский язык? // Снайпер. 2021. 22 марта. URL: https://zen.yandex.ru/media/id/ 604244 eb28b09b0b523d638f/suscestvuet-li-ukrainskii-iazyk-60584824f629c85c2de582e9 (дата обращения: 10.06.2021).

30. Так наречен «македонски език» е вторична норма на книжовния български език // Епицентър. 2020. Ноември 20. URL: http://epicenter.bg/article/SBP--T--nar---makedonski-ezik--e-vtorichna-norma-na-knizhovniya-balgarskiezik/232118/6/0 (дата обращения: 10.06.2021).

31. Украинский язык был придуман в австрийском Генштабе. Так ли это? // История России. 2020. 18 ноября. URL: https://zen.yandex.ru/media/history_russian/ukrainskii-iazyk-byl-priduman-v-avstriiskom-genshtabe-tak-li-eto5fa7d9023a59d85105b1181b (дата обращения: 10.06.2021).

32. Украинский язык и Русский мир // Международная жизнь. 2021. 7 января. URL: https://zen.yandex.ru/ media/id/5c62e2c6ae6f0200adeabbc4/ukrainskii-iazyk-i-russkii-mir-5ff6bba5af142f0b17b59e24 (дата обращения: 10.06.2021).

33. Украинский: язык, диалект, наречие или «селюковский говор»? // Исторические наперстки. 2021. 11 мая. URL: https://zen.yandex.ru/media/id/5ef8896c0d13dd78e21972de/ukrainskii-iazyk-dialekt-narechie-ili-seliukovskii- govor609a8491c7250854e2f37032 (дата обращения: 10.06.2021). 
34. Чахлык Невмырущый... Украинский язык начался с безобидной шутки // Исторические наперстки. 2021. 9 апреля. URL: https://zen.yandex.ru/media/id/5ef8896c0d13dd78e21972de/chahlyk-nevmyruscyi-ukrainskiiiazyk-nachalsia-s-bezobidnoi-shutki-6070268b09f84542a99b5bce (дата обращения: 10.06.2021).

35. Щайнакер Г. Абсурд е да се твърди, че македонският език е просто диалект на българския // Deutsche Welle. 2020. Ноември 11. URL: https://www.dw.com/bg/абсурд-е-да-се-твърди-че-македонският-език-е-простодиалект-на-българския/а-55672477 (дата обращения: 10.06.2021).

36. Эволюция «мовы»: а ведь мог получиться красивый язык... // Исторические наперстки. 2021. 12 мая. URL: https://zen.yandex.ru/media/id/5ef8896c0d13dd78e21972de/evoliuciia-movy-a-ved-mog-poluchitsia-krasivyi-iazyk609ba1b93f44ce7ed10d5600 (дата обращения: 10.06.2021).

Кирчанов Максим Валерьевич, доктор исторических наук,

Поступила в редакцию 28.07.2021 доцент кафедры регионоведения и экономики зарубежных стран ФГБОУ ВО «Воронежский государственный университет» 394018, Россия, г. Воронеж, Университетская площадь, 1 E-mail: maksymkyrchanoff@gmail.com

\section{M.V. Kirchanov \\ "CULTURE OF UNKNOWLEDGE" AS A FORM OF HISTORICAL IMAGINATION AND POLITICAL CULTURE OF RUSSIAN AND BULGARIAN NATIONALISMS}

DOI: $10.35634 / 2587-9030-2021-5-3-357-366$

The author analyzes the images of the Ukrainian and Macedonian languages in the political cultures of Internet users in Russia and Bulgaria. The non-academic concepts of the history and status of the Macedonian and Ukrainian languages are analyzed, and the dependence of such theories on the political and ideological situation is shown. It is assumed that the analyzed interpretations of the Ukrainian and Macedonian languages historically go back to the Russian and Bulgarian nationalisms, which deny the existence of separate Macedonian and Bulgarian languages, which automatically leads to non-recognition of the political legitimacy of countries where these languages are state ones. The author believes that the analyzed levels of political culture of Internet users, on the one hand, contradict the main provisions of academic science. On the other hand, it is assumed that the activity of supporters of the analyzed versions of the Ukrainian and Macedonian languages perception is predominantly virtual, assisting to the formation of the image of the enemy in political cultures. The author believes that the analyzed moods are extremely stable and adaptive, forming symbolically significant dimensions of the Russian and Bulgarian nationalist imaginations in promotion both the concepts of identity and the formation of the images of the Other.

Keywords: political culture, Ukrainian language, Macedonian language, Russian nationalism, Bulgarian nationalism, "regional written norm of the Bulgarian language", language, dialect, language and politics.

\section{For citation:}

Kirchanov M.V. "Culture of unknowledge" as a form of historical imagination and political culture of Russian and Bulgarian nationalisms // Bulletin of Udmurt University. Sociology. Political Science. International Relations. 2021. Vol. 5, iss. 3. P. 357-366. https://doi.org/10.35634/2587-9030-2021-5-3-357-366 (In Russ.).

Kirchanov M.V., Doctor of History, Associate Professor at Department of Regional Studies and Economics of Foreign Countries Voronezh State University Universitetskaya sq., 1, Voronezh, Russia, 394018

E-mail: maksymkyrchanoff@gmail.com 